\section{Sexuality, vulnerability to HIV, and mental health: an ethnographic study of psychiatric institutions}

\author{
Sexualidade e vulnerabilidade ao HIV em saúde \\ mental: um estudo de base etnográfica \\ de instituições psiquiátricas
}

\footnotetext{
${ }^{1}$ Departamento de Processos

Técnico-Documentais,

Universidade Federal do

Estado do Rio de Janeiro,

Rio de Janeiro, Brasil.

2 Associação Brasileira

Interdisciplinar de AIDS,

Rio de Janeiro, Brasil.

3 Instituto de Psiquiatria,

Universidade Federal do

Rio de Janeiro,

Rio de Janeiro, Brasil.

${ }^{4}$ Department of Psychiatry,

Columbia University,

New York, U.S.A

Correspondence

D. S. Pinto

Departamento de Processos

Técnico-Documentais,

Universidade Federal do

Estado do Rio de Janeiro.

Rua dos Oitis 72, apto. 802

Rio de Janeiro, $R J$

22451-050, Brasil.

dianap@globo.com
}

\begin{abstract}
This paper presents data from the ethnographic based formative phase of the Interdisciplinary Project on Sexuality, Mental Health, and AIDS (PRISSMA), sponsored by the National Institute of Mental Health (NIMH) and carried out in two psychiatric institutions in the city of Rio de Janeiro, Brazil. Results from ethnographic observations, focus groups, and key informant interviews with different groups of mental health care providers and day hospital and outpatient mental health clients regarding conceptions of sexuality and HIV vulnerability are described. The results suggest a diversity of notions about sexuality by both groups and point out the high HIV sexual risk in this psychiatric population. This formative phase has served as the basis for the cultural adaptation and creation of a Brazilian intervention for HIV prevention in the severely mentally ill, the feasibility of which has been successfully evaluated in the pilot phase.
\end{abstract}

Sexuality; Health Vulnerability; HIV; Mental Health
Diana de Souza Pinto 1,2

Claudio Gruber Mann 2,3

Milton Wainberg 4

Paulo Mattos 3

Suely Broxado de Oliveira 2,3

\section{Introduction}

The world HIV/AIDS epidemic frequently affects the most vulnerable members of a society. Individuals with severe mental disorders are an example of this reality, with high HIV infection rates in urban communities worldwide. The observed prevalence rates were $3.1 \%$ to $22.9 \%$ in the United States, $6.5 \%$ in Europe, $1.9 \%$ in Asia, and $23.8 \%$ in Africa ${ }^{1,2}$. Almeida 3 , in a pioneering study on seroprevalance in this group in Brazil, documented a rate $(1.6 \%)$ in a psychiatric hospital in the State of Minas Gerais that was approximately three times that of the general population $(0.65 \%)$.

The State of Rio de Janeiro has the second largest number of AIDS cases in Brazil and the highest AIDS incidence rate, with 31.6/100,000 4. The city of Rio de Janeiro accounts for $89.23 \%$ $(45,316)$ of all the cases reported in the State of Rio de Janeiro 4,5. While HIV transmission formerly occurred mainly among men who have sex with men ${ }^{6}$, there is now a significant increase in transmission among heterosexuals.

Few studies in Brazil have focused on sexual risk behaviors in individuals with severe mental disorders. According to Oliveira $7,63 \%$ of a sample of 109 hospitalized psychiatric patients reported having been sexually active in the previous year; of these, $72 \%$ did not use condoms regularly, although $67 \%$ of all the patients knew about forms of HIV transmission and prevention. In another study 8 using semi-structured interviews, Mann 
\& Oliveira observed that $50 \%$ of a sample of 55 female and 68 male patients in a day hospital had been sexually active in the previous year; $28 \%$ reported using condoms, while $60 \%$ reported never having using them.

Although sexuality has serious implications for mental health services, few studies have been performed in this area 9,10. Sexuality has received relatively little attention in medical research, in contrast with the current media culture, featuring abundant messages of a sexual content 11 . The interest awakened by AIDS research has brought in its wake an interest in qualitative methods, to the extent that it provides ideal tools for understanding human behavior by investigating the cognitive maps, beliefs, attitudes, norms, and values underlying the behavior of participants in the creation of specific socio-cultural contexts 12 .

Ethnography, by taking a close-up view of how interactions and relations are constructed and multiple identities are negotiated in the midst of hospital institutions, is capable of expanding the horizons concerning the multiple worldviews of patients and the health care staff who jointly form a mosaic of beliefs, values, and behaviors that are not amenable to being merely grouped in binary sets.

\section{The Interdisciplinary Project in Sexuality, Mental Health, and AIDS}

The Interdisciplinary Project in Sexuality, Mental Health, and AIDS (PRISSMA) is a multidisciplinary and collaborative study resulting from the meeting of researchers from Columbia University (United States); the Institute of Psychiatry, Federal University in Rio de Janeiro (IPUB/UFRJ); and the Brazilian Interdisciplinary AIDS Association (ABIA), sponsored by the National Institute of Mental Health (NIMH R01-65163; 2002-2006). In its first phase, this project aimed to create a Brazilian intervention for the prevention of HIV infection in male and female clients of mental health services (day hospital and outpatient clinic), based on interventions already tested in other countries. The secondary objective was to train local mental health professionals to develop effective Brazilian prevention strategies and thus allow the reduction of HIV risk behaviors by Brazilian users of mental health services with severe mental disorders. The research was conducted in three phases. The first phase used a qualitative methodology with an ethnographic base. Ethnographic observations, focal groups, and interviews with key informants were held. The second phase consisted initially of the translation of all the interventions already tested and available in the literature for HIV/AIDS prevention in users of mental health services and subsequently in their adaptation using the data obtained during the first phase, involving participation by a group of 20 mental health professionals. The third and final phase consisted of applying the intervention in a course format called "HIV, I'm watching you" (the name was chosen by users of the mental health services themselves).

The current article presents and discusses the data from the formative phase that provided the basis for developing the subsequent intervention, using the ethnographic methods described here. The themes "sexuality" and "vulnerability to HIV" were chosen due to their relevance for the development of the intervention.

\section{Context and methods}

The ethnography was conducted from January to April 2003 in two adjoining psychiatric institutions, IPUB/UFRJ, the hospital focus of the ethnography, and its satellite clinic, the Philippe Pinel Institute (IPP), also under Federal administration. Both are located in the Botafogo neighborhood in the South Side of the city of Rio de Janeiro and provide treatment in the emergency, outpatient, and day hospital units.

\section{Ethnographic observations}

The basis for ethnographic work is interaction between the researchers/observers and the group to be studied, in such a way that the researchers' presence and attitudes are not viewed as something strange 13 . Denzin \& Lincoln 14 , recognizing the inherent complexity of the task of defining qualitative research, highlight some of the general characteristics, including the lack of neutrality in the researcher, who employs interpretative practices that make the observed world visible while simultaneously transforming it. The objective of ethnographic observation is to understand the practices, interactions, and events taking place in a given context. The observational procedures contribute to the construction of a reality which is already the result of social construction processes 15 . To the extent that such processes occur, the observation allows portraying the reality of the observed place, producing texts and describing events through field notes.

For three months, two research assistants (one male and one female) conducted daily observations and recorded them as field notes. They spent a total of 350 hours observing the hospital environment, identifying places, persons, routines, and the application of institutional policies 
in the women's and men's emergency units, therapeutic workshops, yards, gardens, and canteens in both institutions.

These ethnographic observations allowed a detailed description and more in-depth understanding of both the context as well as the institutional culture in which the mental health professionals and clientele were immersed. The observations also allowed an approach to the study subjects' perspectives and worldviews and the meanings they ascribe to their own experiences and behaviors 16 .

The observations also informed the development of the stages following the formative phase, namely the focus groups and interviews with key informants, to the extent that they functioned as an initial roadmap for understanding the field, elaborated in greater depth in the two subsequent stages.

\section{Focus groups}

Focus group discussions allow a dialogue between different members of the group and can provide elements for understanding the intersubjective representations of the social actors' cultural norms in their daily lives. As highlighted by Flick 15, one creates an interactive situation that is closer to daily life than allowed by the normal encounter between interviewer and interviewee in an individual interview. Besides encouraging an exchange of experiences and points of view on the topics under investigation 15 , focus groups allow the researcher to pose questions to be examined in greater depth during the interviews with key informants, the last stage in the formative phase of our research. The objective of the focus group is to investigate the beliefs, values, attitudes, and motivations related to the behaviors of different populations in specific social contexts 17 , assessing the extent to which the participants share an opinion on the topic under discussion 15. In our research, such groups aimed to investigate the cognitive map (representations, ideas, prejudices etc.) of the participants in the two psychiatric institutions and the prevailing concepts on sexuality, mental illness, risk perception, and vulnerability, among others.

Nine focus groups were held, lasting an average of 90 minutes each: three with the professionals from both institutions, with a total of 27 participants (17 women and 10 men), with ages ranging from 28 to 67 years. Each of the three focus groups with professionals was divided into: administration (administrators, $\mathrm{n}=5$; 2 women/3 men) linked to patient care (psychiatrists, nurses, psychologists, $\mathrm{n}=13$; 10 women $/ 3$ men) and not linked to patient care (maintenance, reception, administrative department, $\mathrm{n}=9 ; 4$ women/5 men).

We held six focus groups with the patients from the IPP, totaling 45 participants (26 women/19 men), with ages ranging from 24 to 55 years. We chose to hold the focus groups in this institution, because unlike the IPUB, these participants would not be exposed to the intervention in the subsequent phase of the research, thus avoiding influencing the subjects, since the focus groups debated some of the topics that were part of the intervention (knowledge on forms of HIV transmission, different types of condoms, etc). In order to obtain a wider variety of opinions and approaches on the topics, we held two mixed focus groups $(\mathrm{N}=17)$, two with male members only $(\mathrm{N}=13)$, and two with female members only $(\mathrm{N}=15)$.

Selection of the staff participants was based initially on a list that included the names of professionals (physicians, nurses, psychologist, social workers, occupational therapists, nutritionists) and technicians (a laboratory technician and nurse aides and technicians) whose roles were considered crucial to the management of the institutional routine at IPUB/UFRJ.

We issued each professional an invitation in which we explained the group's objective and the importance of their specific participation. Care in the scheduling of focus groups, respecting the professionals' shifts and duties (information that had been retrieved through the ethnographic observations) was another important factor for attendance by the majority of the professionals. The participants in the clientele's focus groups were recruited personally from among the patients at the IPP, whom the research team assessed as being capable of expressing their ideas verbally. All the groups were tape-recorded following prior written informed consent on forms provided by the research ethics committees of the two Brazilian institutions and Columbia University. The exclusion of video recording in order to ensure confidentiality was written into the Term of Consent signed by the clientele. Gender criteria (aimed at ensuring equal representation for men and women) and the participants' time availability were also considered in both groups.

Each focus group was led by a pair of team researchers, a man and a women, with prior experience with group work, properly trained and supervised to conduct this activity in such a way as to guarantee and encourage the contributions and involvement of all the participants.

In the case of the patients' focus groups, after the group sessions ended the participants filled out a brief activity evaluation form, a crucially important document for us to assess the possible 
existence of any adverse effect. Some questions such as HIV testing, sexuality, and condom use might potentially raise concerns related to prior personal experiences, which in fact occurred with one female participant. After this particular situation was reported, a researcher with experience in HIV test counseling followed up on the case and reached a successful outcome.

Holding focus groups requires constructing a topic guideline 17 that defines some questions/ themes that serve as guidelines for the moderator to lead the discussion in such a way as to meet the objective. In our research, these themes were based on questions found in the ethnographic observations, and the focus groups were an important source of further elaborating on them.

The topic guidelines 18 approached questions on: the sexuality of individuals with mental disorders (experiences, representations, stigma, linguistic labels, attitudes, and norms in relation to risk behaviors and prevention), the exercise of sexuality inside and outside the institution, and the relationship between STDs/AIDS and mental illness.

\section{Interviews with key informants}

While conducting the focus groups, we identified both users and professionals/technicians called key informants 19 who were invited verbally and individually to give interviews by which we delved into greater depth on the themes that emerged from the two previous stages in the formative phase. These interviews followed a script with open questions - "What does sexuality mean to you?" - dealing with the principal topics, but also allowing interviewees to expound on other topics of interest to them. The interview guide also specifically approached the configuration of the intervention in relation to operational and logistic issues and themes such as family, religion, alcohol and drug use, and homosexuality. Selection of the interviews was based initially on the participants' input in the focus groups and their availability/willingness to meet with us. Two interviewees who had not participated in the groups were also selected due to their widespread recognition within the institutional routines. Sixteen interviews were held, lasting an average of 45 minutes: 10 with IPP patients ( 6 men and 4 women) and 6 with IPUB professionals (2 men and 4 women).

The interviewers, the same individuals who led the focus groups, followed the procedures from the previous stage, i.e., the interviews were tape-recorded according to the prior informed consent form provided by the interviewer.

\section{Qualitative data analysis}

Use of the ATLAS.ti software (Technische Universität Berlin, Berlin, Germany) allowed filing and organization of the formative phase data, recorded in the field notes and transcriptions from the focus groups and interviews. The list of codes to be applied to the data resulted in a conjugation of the most relevant themes orienting the formative phase (for example, perception of sexuality, vulnerability etc.) and the high frequency of these themes in the data set. The notion of discourse as a jointly constructed social practice, oriented by the interpretative context in which it occurs 20 , provided the basis for analyzing the results generated by the program.

\section{Results}

In one of the ethnographic observations, a female patient provides an explanation of the underlying principle in the ethnographer's view: "Here, if you observe well, you don't need to ask anybody anything, you see everything”. Likewise, scenarios, smells, conversations, organization of space, and other constitutive aspects of the observed communities are other objects of detailed descriptions by the researcher/ethnographer.

The adaptation/creation of an intervention for HIV prevention requires the adoption of an ethnographic methodological perspective in order to grasp the complex social reality of the psychiatric institution, which is constructed by its various agents. We were especially interested in understanding what are commonly considered private themes, viewed as secret or taboo in relation to sexuality, like the various concepts concerning sexuality, HIV, and condom use, as well as risk perception and behaviors in this population. An excerpt from one of the focus groups with patients in which three women (L, MA, and A) exchange remarks, explains the taboo situation of the subject at hand:

L: "It's a really private thing, forbidden to do".

MA: "Intimate, very intimate..." [several voices]

L: “It's a very intimate thing, it's forbidden to talk about it, to think about it, too, even thinking about it is forbidden".

Interviewer: "Even thinking about it is forbidden?”.

A: "Yeah, even thinking about it is forbidden". 


\section{Various concepts on sexuality}

One of the particularly relevant themes for our research was how mental health service clients, professionals, and administrative employees (doormen, receptionists, administrative assistants, cleaning and maintenance personnel etc.) conceive of sexuality in the context. We specifically intended to grasp to what extent the patients' sexuality was perceived by the social actors. A wide range of notions emerged, including the concept that sexuality in the wards is something primitive, void of affection, as illustrated by the following excerpt from one of the first ethnographic observations in which the researcher retells a remark by one of the clients (all the names have been changed to protect the participants' confidentiality):

"[Pablo] said that sex [in the ward] is a weird thing, with no affection, no love. It's a grotesque, animalistic thing that 'brings out the animal inside you'. 'All the dudes care about is humping, no matter where or with whom, it's an ugly thing, animalistic, you see the monster inside you appearing. (...) It's animal-like, with no affection. Just stick your cock in and hump away" (Ethnographic observation 07).

In another observation, in which a nurse is speaking with the research assistant, as she reports on the occurrence of sexual practices on the ward, she voices the frequent view of clients' sexuality as a symptom of their disease (from the mental health professionals' perspective):

"Look, sexuality has always existed and will always be present, there's no way to turn a blind eye to it; among other reasons because this is one of the most striking characteristics of patients with maniac-like syndrome, that they get oversexed and have sex all the time. No matter how some people claim that it doesn't go on in here, it would be a big lie to say it doesn't happen" (Ethnographic observation 69).

In the focus groups with mental health professionals, once again we see the concept they share concerning patients' sexuality associated with their psychiatric condition, referring to hyper-sexuality.

"What they [the nurses] are saying is true, because sexuality in psychiatric hospitals is really exacerbated by the psychiatric patient, it's something we've been hearing about for some time here in the hospital, sexuality in the psychiatric hospitals ..." (Focus group 09).

However, we also found professionals who apparently do not view the patient's sexuality as a manifestation of the mental illness, but rather as an intrinsic aspect of human life:

Bruno: "I once had a professor, who when they asked him about this sexuality business, he, in or- der to complicate things less, said like this 'Look, if a teacher has sex, a student has sex, why can't the patient have sex?' [laughter]".

Nadia: "And is he wrong?".

Bruno: “No ...” (Focus group 09).

This similarity of concepts regarding patients' and non-patients' sexuality was also expressed in the clients' focus group. In the following excerpt, we observe that a female patient highlights the patients' need for sex, but distinguishes it from animals' need, contrasting impulse and desire and underlining the human capacity for reasoning:

"I also think that we [patients] need sex. But when it comes together with desire, and not just doing it for its own sake (...) In my opinion, that's going beyond the limits of nature (...) like animals. They only have sex when they need it, they feel like $i t$, they have instinct, and we have reason (...) we have to use our reason..." (Focus group 22).

The interviews with key informants allowed a more in-depth understanding of the universe of opinions and ways of conceiving the patient's sexuality. For some professionals, sex is viewed as a symptom of the patient's illness, partially corroborating the focus group findings:

"...I think the first thing that surfaces in the patient is his sexual side, I don't know if it's a repressed thing, but they take advantage and release it at a time like this. I also think it really surfaces ..." (Interviews with key informants 02 - Florinda, administrative staff).

In an interview, a psychiatrist expressed different ways of perceiving patients' sexuality. Like other professionals that were interviewed, she also emphasized the patients' "exacerbation of sexuality" and "impulsiveness", identifying the implications for prevention work, as in the first excerpt. In the following sequence, she suggests that patients' sexuality is an integral aspect of their lives, as with anyone else.

Manuela: "I think that this, for them, who have that impulsiveness thing, much more, that much more exacerbated thing, this is without a doubt much more dangerous. Some of them are even aware, but it's a minority (...), and I think even those who are aware of these risks, it's (...) I think it just consolidates this as constant work, like really awareness-raising, you know?".

Interviewer: "And how do you view sexuality in the mental health client?".

Manuela: “Actually, I don't even think they're that different. I think that it's just part of a whole. (...) And sexuality is part - in my opinion, I think that for them in the majority of cases - of life, of their day-to-day" (Interviews with key informants, 04 - Manuela, psychiatrist). 


\section{Sexuality, gender, and mental illness}

In the focus groups and interviews, the theme of sexuality was frequently related to gender issues among the users of mental health services. Some of the professionals working directly in patient care highlighted the differences between men and women in exercising their sexuality, with women identified as taking the initiative, as suggested in the following excerpt:

"The women were more on the lookout for sex than the men. They went for it. It was amazing. If the men were more laid-back, the women insisted more with them. They got to the point where if I was on night duty, several times in the middle of the night I'd have to go there in the middle of them (...) to pull them off top [of the men] (...) hey, come on, don't go. (...) My God!" (Focus group 09).

In relation to sexuality, the professionals in the group also viewed female patients as more "agitated" and "excited":

"... and this here [pointing to the place] is the women's ward, exactly because the women get very, yeah, excited, not sexually, in the psychomotor sense, and much more than the men, to the point that the women's ward is much more, how do you say it?, quote-unquote agitated, than the men's ward" (Interviews with key informants, 06 - Plínio, administrative staff member).

We also found diverse opinions among the professionals, some reacting to the generalizations and commonplace beliefs about female patients' sex drive:

"For a long time [it was thought that] men had drive, but not women. I think this has changed, right? A long time ago. Women have as much drive as men. And there's also a certain myth, right? That [in mental illness], the woman has more exacerbated sexuality. (...) That's it, if the woman has a [psychiatric condition] (...) it's true for both women and men, men, too, (...) So I don't think this line of reasoning leads anywhere" (Interviews with key informants, 05 - Raquel, psychiatrist).

Meanwhile, in the interviews with administrative staff, we found a variety of notions on the relationship between sexuality and mental illness:

"I think that recently, based on what I've seen, I think that [patients' sexuality] is equaling out, cause I see so much brutality from what I hear, see in the newspapers (...) I think it's equaling out because there's sexual harassment both outside the Institute and inside, so I think it's the same thing" (Interviews with key informants, 02 - Florinda, administrative staff).

Still, one male patient mentioned gender differences in relation to sexuality during an interview. People attribute values to men that high- light instinct and impulse. For women, the attributes are normally related to emotions:

"I think men have more of a fixed idea about sex than women, and the men themselves are $a$ little more perverted (...) that thing about idolizing eroticism, nudity is something that men are more keen on doing (...) men are more unfaithful, they like the loose women more, even married men, from any class, workers or business men, they're always looking for prostitutes. (...) From my point of view as a man, women are more emotional, they're usually a little more sensitive, and they're more discriminating, more ethical than men" (Interviews with key informants, 09 - Fauzi, patient).

\section{Psychiatric patients' vulnerability \\ to HIV/STDs}

In our ethnographic observations, there were numerous accounts of sexual relations without condoms in the institution, as in the following excerpt:

"When he told about sex on the wards, he said it was commonplace, that it was absolutely unprotected sex, but usually between two consenting individuals, and that the women usually took the initiative more than the men, and that they had already come on to him, since he said the women patients had a liking for him" (Ethnographic observation 02).

Data from the interviews suggest that the staff consider most of the patients vulnerable to STDs/AIDS, since they have difficulties personifying the risk:

"I myself, as a health professional, when you're working with this (...) We know, right? Look, what we see, people are there, listening and saying: 'No, it won't happen to me.' I think for them, with that impulsiveness, that much more exacerbated thing, it's without a doubt (...) much riskier. Some of them are even aware [of the risk of STDs/HIV]" (Interviews with key informants, 04 - Manuela, psychiatrist).

\section{Risk perception and condom use}

Due to the numerous reports of unprotected sex, one of the crucial points in the focus group discussions was the patients' risk perception towards sexually transmitted diseases, especially AIDS. When we approached this topic, we found a wide range of beliefs and opinions. In the following quote, one patient expresses his indifference towards the risk of catching HIV:

“For me, it's no big deal, I couldn't care less. I fuck any, any (...) I fuck any girl on the street. I fuck with AIDS, without AIDS, without a condom [really...]" (Focus group 29). 
In another group, a patient shows that he does not see himself as being exposed to an STD or AIDS, despite not using condoms:

"I've had almost no diseases at all, thank God. Before my deceased wife, I had a lot of girls, a lot of chicks, a lot of women, but I never ran the risk of catching any disease" (Focus group 15).

In the following quote, a patient recognizes the risk of STDs/AIDS, but reports that he continues to engage in unprotected sex:

"But as for protection, you do have to protect yourself. But I'm even doing something that I shouldn't, because I'm having sex with a girl, and I'm not using condoms, I think it's uncomfortable, and I have sex with her, I know her, but that's the question, do we really know someone? (...) But am I doing the right thing? Apparently not, I'm beginning to think I'm not doing the right thing, that the right thing is to use condoms" (Focus group 29).

On the other hand, in the women patients' focus group, one participant stated her belief that prevention is the best way to protect against curable or incurable diseases.

"Now in the case of sex, you're going to ask about protection because there's no cure for AIDS (...) We should protect ourselves against any disease, whether it's curable or not. Because I have this thing, ever since I was a kid I've heard it, and remembered: an ounce of prevention is better than a pound of cure" (Focus group 22).

The interviews with both the administrative staff and the professionals involved directly in patient care also showed relevant findings for understanding how patients perceive themselves at risk and to what extent this perception may or may not result in condom use:

"Yesterday I was even commenting, I was talking with this patient, who said, "I'm just picking up nine condoms [at the dispensary], I don't think it's enough'. I asked, 'But are you going to use all of them?'. She said: 'I use them, I use a lot of them.' In other words, she's aware of the disease (...) The women generally remark, 'Oh! I'm involved with a patient here, but we can't have sex without condoms"' (Interviews with key informants, 02 - Florinda, administrative employee).

\section{Conclusion}

In the current article, we analyze ethnographic data from the PRISSMA project relating to the themes of concepts and exercise of sexuality and vulnerability to $H I V$. This phase provided the basis for the creation/adaptation of an intervention for HIV prevention in clients of mental health services with severe mental disorders, conducted successfully at the IPUB/UFRJ in Rio de Janeiro ${ }^{21}$. The reports contained in the ethnographic observations suggest the existence of sexual practices inside the institution, which was also identified in the focus groups and interviews with key informants. As a whole, the qualitative methodological techniques revealed a mosaic of concepts, beliefs, and attitudes towards sexuality by clients of mental health services, while it was not possible to identify intra-group unanimity of concepts. The theme of sexuality and related issues have still received little discussion and are viewed alternatively as a manifestation of bestial traits, a symptom of the mental illness, or as an intrinsic aspect of the human condition.

With regard to patients' sexuality and gender, the data suggest some shared intra- and intergroup concepts. Some of the professional staff working with patients, as well as male patients, tended to view female patients as "forward", i.e., responsible for taking the initiatives in relation to sex. Meanwhile, the vast majority of the administrative staff believed that there are no differences in sexuality between users and non-users of mental health services.

These distinct perspectives raise some possible (and not mutually exclusive) interpretations. On the one hand, they may reflect the participants' own difficulties in dealing with such a complex theme, often considered a "private matter"; on the other, they may point to some general approaches that each group adopts in the absence of discussions and/or institutional training to help them deal with this issue on a routine daily basis. From the perspective of the patients who participated in the study, there appears to be a consensus: men are ascribed attributes that highlight the "animal" side of their sexuality, while women are characterized mainly by their emotional side.

The data also attest to this population's vulnerability. Both patients and staff report patients' sexual practices (both inside and outside the institution) without any protection or with inconsistent condom use. Still, while in the general population the gender difference involves greater vulnerability among women, who generally experience difficulties in negotiating condom use with their partners (thus providing a possible explanation for the most recent epidemiological data on the AIDS epidemic in Brazil, showing a significant increase in HIV infection in women 4,5 ), our data do not corroborate this association between female gender and greater vulnerability. Rather, they indicate unprotected sexual practices initiated by both sexes with no regard for condom use (or thus for its negotiation). Further research on this issue is therefore 
necessary. The psychiatric population studied here showed evidence that the lack of personal perception of risk, as in the general population ${ }^{22}$, is still one of the major challenges for STD/AIDS prevention.

We believe that the relevance of the findings from the formative phase of the research, partially described here, have fundamental implications for research in the area of interventions for HIV prevention in this population group. First, they attest to the pressing need for intervention research in the area, given the great vulnerability of mental health clients. Second, they highlight the need, as expressed by all three groups of professionals, for greater involvement in training and discussion on how the institution can better deal with the exercise of sexuality by patients. Finally, they reveal the importance of the contributions by participants for creating an HIV prevention intervention that is culturally adapted to the local realities, given their specificity. To develop such an instrument is a complex task, since the behavior changes needed for future application do not depend only on information concerning sexual life or HIV. They involve socio-cultural aspects like sexual identity, division of social gender roles, beliefs, family expectations, etc. 23 , all adequately researched with the qualitative methodological techniques described above. The hope is thus to at least partially fill a gap in the understanding of complex aspects in HIV prevention efforts for clients of mental health services.

We were truly amazed by a quote from one patient, recorded in field notes: "I can't choose.
I'm chosen". Although brief, this statement strikingly represents the multiplicity and complexity of issues involved in psychiatric patients' experience, who are deprived of the right to exercise choice in various areas, including the choice of a partner. One of the cruelest implications and consequences of this deprivation is the HIV prevalence rate in this population, which in Brazil is some three times that of the general population, as described in the introduction.

According to ethnographer Michel Agar 19 (p. 65), “without science, we lose our credibility; without humanity, we lose our ability to understand others". We believe that in these institutions the formative phase not only prepared the PRISSMA project team in its task of creating and adapting an HIV prevention intervention, but also made it more human.

\section{Limitations}

The findings analyzed in this article cover a few of the many aspects in the ethos of two psychiatric hospitals located in a major Brazilian city and which permeate the creation and cultural adaptation of interventions for a psychiatric population. Other similar studies are needed to better understand the complex aspects involved in themes that are taboo in the psychiatric population, such as patients' sexuality and vulnerability.

\section{Resumo}

Este artigo apresenta dados da fase formativa, de base etnográfica, do Projeto Interdisciplinar em Sexualidade, Saúde Mental e AIDS (PRISSMA) patrocinado pelo National Institute of Mental Health (NIMH) e desenvolvido em duas instituições psiquiátricas da cidade do Rio de Janeiro, Brasil. São descritos e discutidos os resultados obtidos nas observações etnográficas, grupos focais e entrevistas com informantes-chave realizados com diferentes grupos de profissionais de saúde mental e usuários de saúde mental do hospital-dia elou em tratamento ambulatorial, relativos às concepções de sexualidade e vulnerabilidade para o HIV.
Os resultados sugerem uma diversidade de relatos e noções sobre o exercício da sexualidade por ambos os grupos e aponta para o alto risco sexual para o HIV nessa população psiquiátrica. Esta fase formativa embasou a adaptação cultural e a criação de uma intervenção brasileira para prevenção desse vírus em portadores de transtornos mentais graves cuja viabilidade foi avaliada com sucesso na fase piloto.

Sexualidade; Vulnerabilidade em Saúde; HIV, Saúde Mental 


\section{Contributors}

D. S. Pinto and C. G. Mann collaborated in elaborating the theoretical framework, methodology, data analysis, and drafting and review of the manuscript. M. Wainberg and P. Mattos collaborated in the drafting and review of the article. S. B. Oliveira participated in the drafting of the methodology and in the data analysis.

\section{Acknowledgments}

Dr. Milton Wainberg's participation in this study was funded by the National Institute of Mental Health (R01 MH65163). For their enormous contributions to the Interdisciplinary Project on Sexuality, Mental Health, and AIDS (PRISSMA), the authors wish to thank the clients of the Institute of Psychiatry, Federal University in Rio de Janeiro (IPUB) and the Phillipe Pinel Institute, the mental health professionals and other staff members, and the Research Community Advisory Board. Researchers who provided us with inestimable support for writing this article include Carlos Veloso Filho, Fernanda Gomes Luz, and Tatiana Dutra Furniel.

\section{References}

1. McKinnon K, Cournos F, Herman R, Le Melle S. HIV and people with serious and persistent mental illness. In: Citron K, Brouillette M-J, Beckett A, editors. HIV \& psychiatry: a training and resource manual. Cambridge: Cambridge University Press; 2005. p. 138-52.

2. Rosenberg SD, Goodman LA, Osher FC. Prevalence of HIV, hepatitis B, and hepatitis C in people with severe mental illness. Am J Public Health 2001; 91:31-7.

3. Almeida RC. Comportamentos, situações de risco e exposição aos marcadores sorológicos dos vírus da imunodeficiência humana, hepatites B e C, vírus linfotrópico de células humanas, sífilis e outras doenças sexualmente transmissíveis em pacientes psiquiátricos internados em hospital público [PhD Dissertation]. Belo Horizonte: Universidade Federal de Minas Gerais; 2002.

4. Ministério da Saúde. Boletim Epidemiológico AIDS e DST 2005; Ano II; no. 1.

5. Ministério da Saúde. Boletim Epidemiológico AIDS e DST 2005; Ano III; nº 1.

6. Parker R. Corpos, prazeres e paixões: cultura sexual no Brasil contemporâneo. Rio de Janeiro: Editora Best Seller; 1991.
7. Oliveira SB. Avaliação do comportamento sexual, conhecimentos e atitudes sobre AIDS: um estudo entre indivíduos internados com distúrbios mentais. In: Venâncio AT, Leal EM, Delgado PG, organizadores. O campo da atenção psicossocial. Rio de Janeiro: Te Corá Editora; 1997. p. 343-51.

8. Mann CG, Oliveira SB. Oficina de saúde \& sexualidade: avaliando mudanças de comportamento sexual, conhecimentos e atitudes sobre AIDS dos USM. In: Anais do Fórum 2000: I Fórum e I Conferência de Cooperação Técnica Horizontal da América Latina e do Caribe em HIV/AIDS e DST. Rio de Janeiro: Coordenação Nacional de DST/AIDS; 2000. p. 101.

9. Buckley PF, Wiechers IR. Sexual behavior of psychiatric inpatients: hospital responses and policy formulation. Community Ment Health J 1999; 6:531-6.

10. Krumm S, Kilian R, Becker T. Psychiatric inpatient care and sexuality. Psychiatr Prax 2004; 31:212-7.

11. Mossman D, Perlin ML, Dorfman DA. Sex on the wards: Conundra for clinicians. J Am Acad Psychiatry Law 1997; 25:441-60.

12. Seal DW, Bloom FR, Somlai AM. Dilemmas in conducting qualitative sex research in applied field settings. Health Educ Behav 2000; 27:10-23. 
13. Russel BH. Research methods in anthropology. New York: Altamira Press; 1995.

14. Denzin NK, Lincoln YS. Handbook of qualitative research. Thousands Oaks: Sage Publications; 1994.

15. Flick U. Uma introdução à pesquisa qualitativa. 2ạ Ed. Porto Alegre: Editora Bookman; 2004.

16. Glesne C. Becoming qualitative researchers: an introduction. 2nd Ed. New York: Longman; 1999.

17. Gaskell G. Entrevistas individuais e grupais. In: Bauer MW, Gaskell G, organizadores. Pesquisa qualitativa com texto, imagem e som. 2a Ed. Petrópolis: Editora Vozes; 2003. p. 64-89.

18. Wainberg M, Gonzalez A, McKinnon K, Elkington K, Pinto D, Mann CG, et al. Targeted ethnography as a critical step to inform cultural adaptations of HIV prevention interventions for adults with severe mental illness. Soc Sci Med 2007; 65:296-308.

19. Agar MH. The Professional Stranger: an informal introduction to ethnography. 2nd Ed. New York: Academic Press; 1996.
20. Gill R. Análise do discurso. In: Bauer MW, Gaskell G, organizadores. Pesquisa qualitativa com texto, imagem e som. 2a Ed. Petrópolis: Editora Vozes; 2003. p. 244-70.

21. Wainberg ML, McKinnon K, Mattos PE, Pinto D, Mann CG, Oliveira CS, et al. A model for adapting evidence-based behavioral interventions to a new culture: HIV prevention for psychiatric patients in Rio de Janeiro, Brazil. AIDS Behav 2007. http://www.springerlink.com/content/ 13r3w50161713q53/.

22. Gasiorowicz M, Llanas MR, DiFranceisco W, Benotsch EG, Brondino MJ, Catz SL, et al. Reductions in transmission risk behaviors in HIV-positive clients receiving prevention case management services: findings from a community demonstration project. AIDS Educ Prev 2005; 17(1 Suppl A):40-52.

23. Oliveira SB. Loucos por sexo: um estudo sobre a vulnerabilidade dos USM para o HIV [Masters Thesis]. Rio de Janeiro: Instituto de Psiquiatria, Universidade Federal do Rio de Janeiro; 1998.

Submitted on 06/Mar/2006

Final version resubmitted on 22/Nov/2006 Approved on 18/Jan/2007 
